\title{
Turning Scientific Knowledge into Regulation: Effective Measures for Noise Mitigation of Pile Driving
}

\author{
Carina Juretzek (D), Ben Schmidt and Maria Boethling * \\ Bundesamt für Seeschifffahrt und Hydrographie (BSH), Bernhard-Nocht Straße 78, 20359 Hamburg, Germany; \\ carina.juretzek@bsh.de (C.J.); ben.schmidt@bsh.de (B.S.) \\ * Correspondence: maria.Boethling@bsh.de
}

Citation: Juretzek, C.; Schmidt, B.; Boethling, M. Turning Scientific Knowledge into Regulation: Effective Measures for Noise Mitigation of Pile Driving. J. Mar. Sci. Eng. 2021, 9, 819. https://doi.org/10.3390/jmse9080819

Academic Editors: Michel André and Christine Erbe

Received: 14 June 2021

Accepted: 21 July 2021

Published: 29 July 2021

Publisher's Note: MDPI stays neutral with regard to jurisdictional claims in published maps and institutional affiliations.

Copyright: (c) 2021 by the authors. Licensee MDPI, Basel, Switzerland. This article is an open access article distributed under the terms and conditions of the Creative Commons Attribution (CC BY) license (https:/ / creativecommons.org/licenses/by/ $4.0 /)$.

\begin{abstract}
Pile driving is one of the most intense anthropogenic noise sources in the marine environment. Each foundation pile may require up to a several thousand strokes of high hammer energy to be driven to the embedded depth. Scientific evidence shows that effects on the marine environment have to be anticipated if mitigation measures are not applied. Effective mitigation measures to prevent and reduce the impact of pile driving noise should therefore be part of regulation. The role of regulators is to demonstrate and assess the applicability, efficiency and effectiveness of noise mitigation measures. This requires both, scientific knowledge on noise impacts and the consideration of normative aspects of noise mitigation. The establishment of mitigation procedures in plans and approvals granted by regulatory agencies includes several stages. Here, we outline a step-wise approach in which most of the actions described may be performed simultaneously. Potential measures include the appropriate maritime spatial planning to avoid conflicts with nature conservation, site development for offshore wind farms to avoid undesirable activities in time and space, coordination of activities to avoid cumulative effects, and the application of technical noise abatement systems to reduce noise at the source. To increase the acceptance of noise mitigation applications, technical measures should fulfil a number of requirements: (a) they are applicable and affordable, (b) they are state-of-the-art or at least advanced in development, (c) their efficiency can be assessed with standardised procedures. In this study, the efficiency of noise mitigation applied recently in offshore wind farm construction projects in the German North Sea is explained and discussed with regard to the regulation framework, including the technical abatement of impulsive pile driving noise.
\end{abstract}

Keywords: ocean noise mitigation; ocean noise regulation; ocean sound measurement

\section{Introduction}

An essential characteristic of the human being is the ability to reach ever new horizons. The development of new technologies is increasingly expanding the reach of human influence on the sea. For a decade now, this has also included the first-time and large-scale exploration of nearshore and offshore sea regions for the generation of green energy as part of the growing Blue Economy. Today's generations of people are shaping and experiencing this new type of development at sea. However, we should bear in mind that marine species also experience the effects of these human activities. The reconciliation of both needs, those of humans and those of marine species, is therefore a process that must accompany these new developments. The most common installation method for foundations of offshore structures in the (southern) North and Baltic Sea is pile driving [1]. A major effort has been made to better understand the risks for adverse effects on the marine environment due to underwater noise during foundation installations by pile driving. These risks have been found to include very relevant adverse effects, such as impaired hearing and temporary habitat loss. Effects of pile driving on marine life and the need for environmental monitoring and noise mitigation measures that invariably accompany impact pile driving, particularly in biologically sensitive subsea habitats, are well described [2]. Alternative 
installation methods such as gravity foundations, suction buckets or vibratory pile driving are either still under development or to date only applicable to specific site conditions. Due to local site conditions, including geological conditions and technical developments, pile driving is expected to remain one of the most common installation methods for the next decade [2-4].

The presence of underwater noise in the ocean and its impacts on marine life have received increasing attention in recent years [5-10]. Science has made progress on both related aspects, the physics of underwater noise and the effects of noise on marine organisms. At the same time, work is underway to research or develop underwater noisereducing technologies for various anthropogenic activities [11,12].

Since 2011, guidance documents for underwater noise measurements during construction of offshore wind farms have been published in Germany, the Netherlands and the UK to provide advice on good practice and to make data comparable [13-15]. This was followed by an international effort to establish a common terminology for underwater acoustics that defines terms and expressions used in the field of underwater acoustics, including natural, biological, and anthropogenic sound by ISO [16]. ISO 18406:2017 [17] describes the methods, procedures and measurement systems for measuring radiated underwater sound generated by pile driving operations using hammer strokes. Furthermore, many research projects have developed models to describe sound generation in the near field and sound propagation during pile driving activities [18-21].

The description of noise criteria and frequency weighting functions for marine mammals grouped according to their hearing abilities [22] has supported noise regulation and mitigation efforts worldwide. In 2019, the proposed noise criteria were revised and evaluated in the light of new scientific findings. Dual exposure metrics are provided for impulsive noise criteria, including the frequency-weighted sound exposure level (SEL) and the unweighted peak sound pressure level (SPL) (expressed in units relative to $1 \mu \mathrm{Pa}$ for water). Exposures exceeding the respective criterion level for each exposure metric are interpreted as causing a predicted temporary threshold shift (TTS) or permanent threshold shift (PTS) onset [22].

The critical role of exposure context in addition to received noise levels has been extensively studied. One review of studies on noise criteria found that behavioural responses in cetaceans (measured using a linear severity scale) are best described by the interaction between sound source (continuous sound, sonar or seismic/explosion) and functional auditory group (a proxy for hearing capabilities) [10]. Importantly, more severe behavioural responses were not consistently associated with higher received noise levels and vice versa. The authors recommend replacing the severity score of behavioural response with a dichotomous approach (response/no response) that can provide a measure of impact in terms of habitat loss and degradation [10].

Based on scientific results, efforts were made to describe regulatory frameworks for mitigating noise from impulsive sources. Further, a frequency-dependent weighting function and numerical thresholds for the onset of temporary threshold shift (TTS) and permanent threshold shift (PTS) were derived for each group of marine mammals from the available data describing the hearing ability and the effects of noise on marine mammals [23].

Acoustic thresholds based on TTS and PTS onset levels for marine mammal auditory groups for assessing the effects of anthropogenic sound were updated and included in a technical guidance published by NMFS [24] for regulatory purposes. The acoustic thresholds according to NMFS [24] are based on dual metrics of cumulative sound exposure level (SEL $\left.\mathrm{L}_{\text {cum }}\right)$ and peak sound level ( $\left.\mathrm{L}_{\text {peak }}\right)$ for impulsive sounds and on $\mathrm{SEL}_{\text {cum }}$ for nonimpulsive sounds.

Policy options to mitigate underwater noise and employ noise abatement systems to reduce the impact on marine life have recently been reviewed [25]. Today, noise emissions can be reduced by placing acoustic barriers around the pile driving operation. Various designs have been developed, using air bubbles, solid barriers, or combinations of these. 
However, regulatory responses to offshore wind farm construction noise have differed. As noted in [25], in Germany and several other Western European countries (e.g., the Netherlands and Denmark), regulations are routinely applied which de facto mandate the use of noise abatement measures such as bubble curtains (see below). On the other hand, noise abatement has not yet been implemented in other countries, including two of the three largest offshore wind energy producers by wattage. Looking at the economic factors, the author [25] concludes that the German approach, based on a command-and-control regulation, has substantially reduced noise pollution from pile driving while allowing renewable energy development to continue, and is therefore the most effective noise management model currently available.

Here, we outline a possible way to build a mitigation strategy and detail a step-wise approach for implementing noise mitigation measures in practice. Furthermore, we present and discuss recent examples of such a regulation scheme in regard of noise mitigation of impulsive pile driving noise by considering representative examples of monitoring data from acoustic measurements with regard to current conditions at offshore construction sites. Moreover, we analyse the noise emissions of mitigated piling in the German Bight from an offshore wind farm cluster at different distances. Additionally, we discuss implications for future monitoring requirements in terms of the variety of processes at the construction site.

\section{Materials and Methods}

As a strictly protected species according to the Habitat directive (92/43/EWG) and the Federal Nature Conservation Act in Germany, the harbour porpoise represents the key species in German waters of the North Sea and Baltic Sea and temporary hearing threshold shift (TTS) in harbour porpoises is classified as injury. Since 2008, the com-pliance with a dual sound pressure threshold criterion for pile driving activities has been mandatory for all wind farm construction projects in the German exclusive eco-nomic zone (EEZ) approved by BSH in order to prevent TTS in harbour porpoises. Fol-lowing the precautionary principle for the protection of harbour porpoises and the marine environment, noise emissions from pile driving at a measuring distance of $750 \mathrm{~m}$ from the piling location must not exceed the dual criterion given by

- $\quad$ an unweighted sound exposure level SEL $\left(\mathrm{L}_{\mathrm{E}}\right)$ of $160 \mathrm{~dB}$ re $1 \mu \mathrm{Pa}^{2} \mathrm{~s}$,

- a zero-to-peak sound pressure level ( $\left.\mathrm{L}_{\text {peak }}\right)$ of $190 \mathrm{~dB}$ re $1 \mu \mathrm{Pa}$.

Frequency weighting has not been included intentionally. Since several thousand blows are required to reach the final penetration depth, a percentile statistic was chosen to account for multiple blows. In this sense, the $\mathrm{SEL}_{05}$ describes the sound exposure level exceeded by $5 \%$ of the total number of SEL measurements.

The sound exposure $E$ is defined as

$$
E=\int_{T_{1}}^{T_{2}} p(t)^{2} d t
$$

and has the unit $\mathrm{Pa}^{2} \mathrm{~s} . \mathrm{T1}$ and $\mathrm{T} 2$ indicate the start and end of the evaluated time span respectively, which includes exactly one hammer stroke here. $p(t)$ is the time-variant sound pressure. For the calculation of the dimensionless level, this ex-pression is divided by the reference $E_{0}$

$$
E_{0}=p_{0}^{2} T_{0}
$$

where $T_{0}$ is defined as $1 \mathrm{~s}$ and $p_{0}$ is defined as $1 \mu \mathrm{Pa}$. The SEL is thus given by

$$
\mathrm{SEL}=10 \log _{10}\left[\frac{\int_{T_{1}}^{T_{2}} p(t)^{2} d t}{p_{0}^{2} T_{0}}\right]\left[\mathrm{dB} \text { re } 1 \mu \mathrm{Pa}^{2} \mathrm{~s}\right]
$$


The $L_{\text {peak }}$ is given by

$$
L_{\text {peak }}=20 \log _{10}\left[\frac{\max (|p(t)|)}{p_{0}}\right][\mathrm{dB} \text { re } 1 \mu \mathrm{Pa}]
$$

The definition of the dual criterion was based on research results on the onset of TTS in a harbour porpoise as a results of a single impulsive sound exposure [12,15].

All acoustic measurements of underwater noise radiated during pile driving requested by competent agencies in Germany follow the specifications of ISO 18406:2017 and the terminology of ISO 18405:2017. Accreditation according to DIN EN ISO/IEC 17025 [26] for ISO 18406:2017 [16] and DIN SPEC 45653:2017 [27] is required from the measuring institutes.

In comparison to $\mathrm{SEL}_{\mathrm{cum}}$, as proposed by NMFS (2016), using percentile statistics of measured SEL to monitor compliance with target values and the performance of noise abatement systems provides a practical and convenient option to monitor and steer the ramming process and the noise abatement systems on a tight schedule. Especially as each pile driving operation is regularly limited to a maximum of three hours, including any deterrence measures and soft-start procedures.

These noise threshold values were purposely defined as unweighted levels which, on one hand, provide a multi-species framework, including the key species, for the development of technical noise mitigation for offshore construction sites. On the other hand, they allow for a robust and standardised monitoring of compliance. In this way, the achievements of the technical targets for noise reduction at the source and the associated reduction of habitat loss due to avoidance and disturbance can be quantified. The compliance with these thresholds requires the application of technical noise abatement measures. Since 2011, the application of such technical noise abatement systems is mandatory at all offshore construction sites in the German EEZ. For a standardised evaluation and documentation of the compliance with the threshold criteria and of the noise exposure of habitats, the noise emissions are monitored and evaluated according at a distance of $750 \mathrm{~m}$ and $1500 \mathrm{~m}$ to the source and in the nearest nature conservation site or alternatively at a distance of a few kilometres to the wind farm according to the Measuring Instruction by BSH [17] and ISO 18406:2017 [18]. Measurements of sound pressure must cover a frequency range of at least $10 \mathrm{~Hz}$ to $20 \mathrm{kHz}$. All acoustic monitoring data and corresponding technical data on noise abatement systems and the construction process during pile driving activities must be delivered to BSH via the e-reporting portal of an expert information system for underwater noise (https:/ /MarinEARS.bsh.de (28 July 2021)) [28], where the data is undergoing a quality assurance before being made available for internal evaluations.

To evaluate the effectiveness of noise abatement systems and the source level of impact hammers for different site and project characteristics, an instruction was specified in Germany and further developed into a national DIN Specification [26]. According to DIN SPEC 45653:2017 [26], reference and test measurements following a standard design are mandatory for every construction project. Standards for assessment procedures, such as the DIN SPEC 45653:2017 [27], are the prerequisite for the development of abatement systems to reduce underwater noise from pile driving and for an effective protection of marine ecosystems.

In this study, we evaluated acoustic measurements for 23 pile driving events from recent offshore wind farm constructions in the German Bight. Acoustic data were recorded by a high quality, temporary monitoring station with a fixed location, corresponding to distances between $1.7 \mathrm{~km}$ and $14.6 \mathrm{~km}$ from the pile driving locations. Acoustic data were also recorded at distances of 750 and $1500 \mathrm{~m}$ to the source, according to the measuring instructions and standards detailed above $[17,18]$. The measurement height above seabed was $1.5 \mathrm{~m}$ for the temporary fixed monitoring station and $2 \mathrm{~m}$ above seabed for the remaining monitoring locations.

All hydrophone data correspond to single-channel recordings (MPEG1 Audio-Layer 3 at the fixed station and PCM Wave-data at 750 and $1500 \mathrm{~m}$ distance) and were recorded 
by autonomous remote measurement systems with a sampling frequency of fs $=44.1 \mathrm{kHz}$. Due to the higher sound pressure levels expected at 750 and $1500 \mathrm{~m}$ distance to the source, the sensitivity of hydrophones at these locations is reduced in comparison to the distant monitoring location, limiting the sensitivity for the higher frequency range above a few kilohertz. Since most of the radiated acoustic energy is well below $1 \mathrm{kHz}$, this is not a limitation for the evaluation of pile driving noise emissions.

Pile driving events analysed here, occurred during the foundation construction phase in a wind farm cluster with installation positions located in water depths between approximately 38 and $40 \mathrm{~m}$. All foundations correspond to monopiles of the same diameter. With respect to the geographic location of the temporary fixed monitoring stations, pile driving event locations can be attributed to a narrow range of source azimuths.

We perform an in-depth analysis regarding certain aspects of interest, in order to study the effects of various noise emissions at the increasingly active construction sites.

All evaluations of the acoustic metrics were performed using BSH's own acoustic evaluation tool BSoundH, which was developed by Fraunhofer IDMT as part of the research and development project SOUND Mapping (BSH project number 10044386) and which is specifically designed for the evaluation of monitoring data in the context of the regulation framework in the German EEZ. The maximum zero-to-peak level $\mathrm{L}_{\text {peak }}$ and the sound exposure level SEL were calculated for each hammer stroke detected. Furthermore, we calculated the equivalent continuous sound pressure level LEQ for the period during pile driving and a few hours before via

$$
\mathrm{LEQ}=10 \log _{10}\left[\frac{1}{T} \int_{0}^{T} \frac{p(t)^{2}}{p_{0}^{2}} d t\right]\left[\mathrm{dB} \text { re } 1 \mu \mathrm{Pa}^{2}\right]
$$

where 0 and $T$ indicate the start and end of the evaluated time span respectively and $p_{0}$ is defined as $1 \mu \mathrm{Pa}$. Here, the duration of each evaluation window $T$ is $5 \mathrm{~s}$. For all quantities, SEL, LEQ and $L_{\text {peak }}$, we determined the exceedance levels of $5 \%, 50 \%, 95 \%$ and the maximum. E.g. the $5 \%$ exceedance level of the $L_{\text {peak }}$ corresponds to the sound pressure level which is exceeded in 5\% of the hammer strokes of a pile driving event. Broadband levels of SEL and LEQ were calculated over the entire measured frequency range without time or frequency weighting. For the SEL and LEQ we further calculated 1/3-octave band levels between $10 \mathrm{~Hz}$ and $20 \mathrm{kHz}$ (IEC 61260).

\section{Results}

In this section, we present recent examples from acoustic monitoring under the noise mitigation framework, which is further detailed in Section 4. In Section 3.1 we analyse the acoustic measurements at 750 and $1500 \mathrm{~m}$ distance and in Section 3.2 we evaluate the measurements from the temporary fixed measurement position, which is at greater distances.

3.1. Results of Pile Driving Noise Monitored at $750 \mathrm{~m}$ and $1500 \mathrm{~m}$ Distance to the Source during $a$ Typical Recent Construction Project in the German EEZ

For more than six years, several noise abatement systems have been successfully applied for ensuring the reliable compliance with the threshold criteria for construction projects in the German EEZ. Since emitted sound pressure levels increase with the pile surface area below the sea surface, and therefore with increasing water depths and pile diameters [1], an ongoing development and adaption of noise abatement systems to these changing conditions is required for maintaining the reliable compliance with threshold values as observed during recent years.

Figure 1 shows resulting values of $\mathrm{SEL}_{05}$ and $\mathrm{L}_{\text {peak }}$ evaluated from acoustic monitoring data recorded at a distance of $750 \mathrm{~m}$ to the source for the 23 pile driving events were considered in this study. Horizontal lines indicate the dual threshold criterion, which indicates a compliance with the regulatory requirements. All but one pile in our data pool were installed using a combination of two noise abatement systems: a noise mitigation screen (IHC-NMS) and a double big bubble curtain (DBBC). For pile number 17, no DBBC 
was used and the IHC-NMS was removed before the second half of the pile driving process.

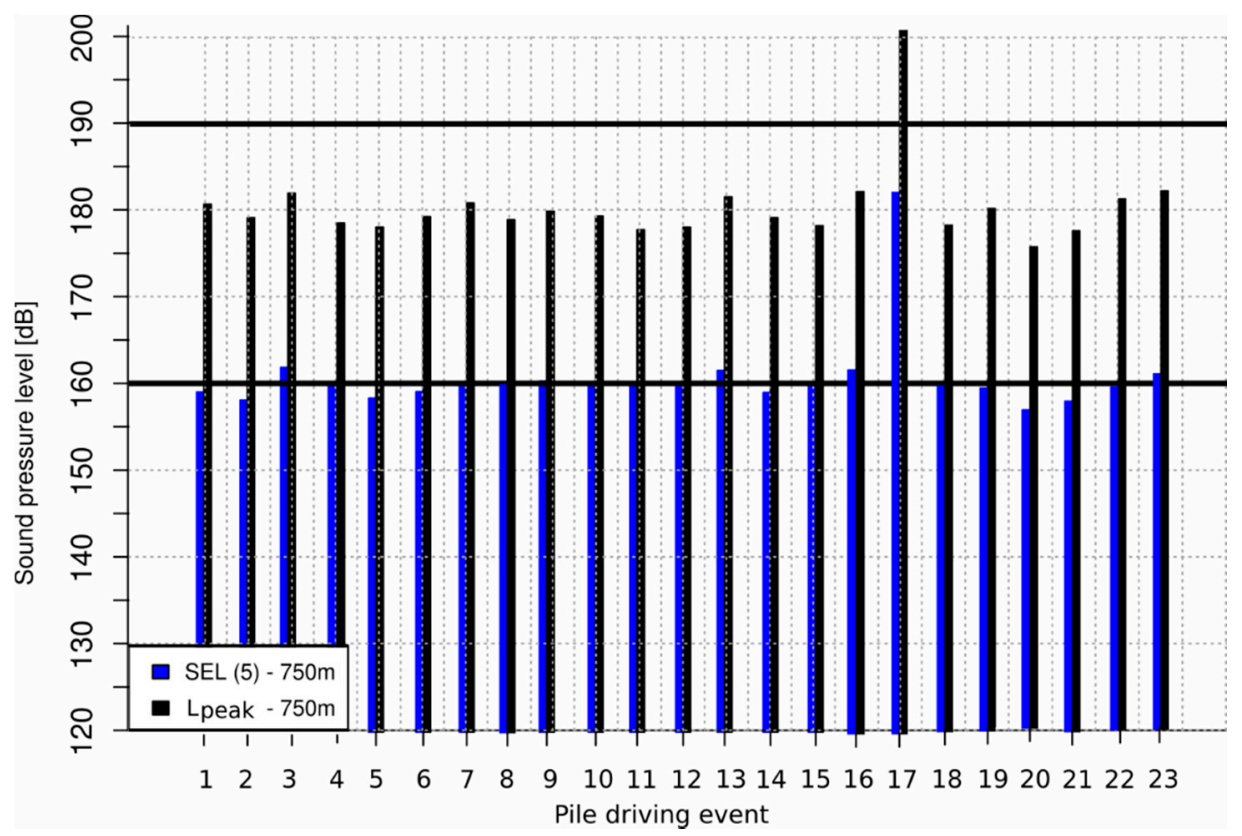

Figure 1. Bar-diagram showing $\mathrm{SEL}_{05}$ (blue, in $\mathrm{dB}$ re $1 \mu \mathrm{Pa}^{2} \mathrm{~s}$ ) and $\mathrm{L}_{\text {peak }}$ (black, in $\mathrm{dB}$ re $1 \mu \mathrm{Pa}$ ) values evaluated from acoustic monitoring data recorded in a distance of $750 \mathrm{~m}$ to the pile driving location in comparison to the dual threshold criterion. Pile number 17 corresponds to the test and reference measurement as detailed in the text.

Resulting $\mathrm{SEL}_{05}$ in $750 \mathrm{~m}$ distance to the source do not exceed a value of $160 \mathrm{~dB}$ for all but five piling events, and none of the mitigated pile driving activities yields a $\mathrm{SEL}_{05}$ above $161 \mathrm{~dB}$. Observed $\mathrm{L}_{\text {peak }}$ values remain well below the threshold of $190 \mathrm{~dB}$ re $1 \mu \mathrm{Pa}$. In contrast, significantly higher sound pressure levels for both metrics are observed for the unmitigated pile driving event, which exceeds both of the threshold criteria with more than $20 \mathrm{~dB}$ for the $\mathrm{SEL}_{05}$ and more than $12 \mathrm{~dB}$ for the $\mathrm{L}_{\text {peak. }}$. Such obligatory test and reference measurements are granted by BSH purposely for the evaluation of the offshore effectiveness of noise abatement systems applied. When construction projects face difficult site conditions, such as increasing water depths and/or new technical characteristics, such as increasing pile diameters, these evaluations are crucial for the assessment of necessary measures and technical development in further projects. In particular, the reduction target to be achieved can be estimated, which yields implications on the handling and optimisation of technical abatement systems. All results of measurements at $750 \mathrm{~m}$ and $1500 \mathrm{~m}$ distance to each pile driving site within the framework of the officially ordered construction monitoring by the regulatory agency are included in technical reports provided to the approval and nature conservation authorities.

For a comparison between the spectra of three different noise abatement system configurations, we consider unmitigated pile driving at pile number 17 , mitigated pile driving at pile number 17 using an IHC-NMS and mitigated pile driving using an IHCNMS and DBBC at pile number 23. For all three cases, we selected four hammer strokes during time spans, which yield a similar hammer energy within a narrow energy range between 2850 and $2890 \mathrm{~kJ}$. Figure 2 shows the resulting spectrograms for the three different configurations evaluated for the acoustic measurements at $1500 \mathrm{~m}$ distance to the pile driving location. 

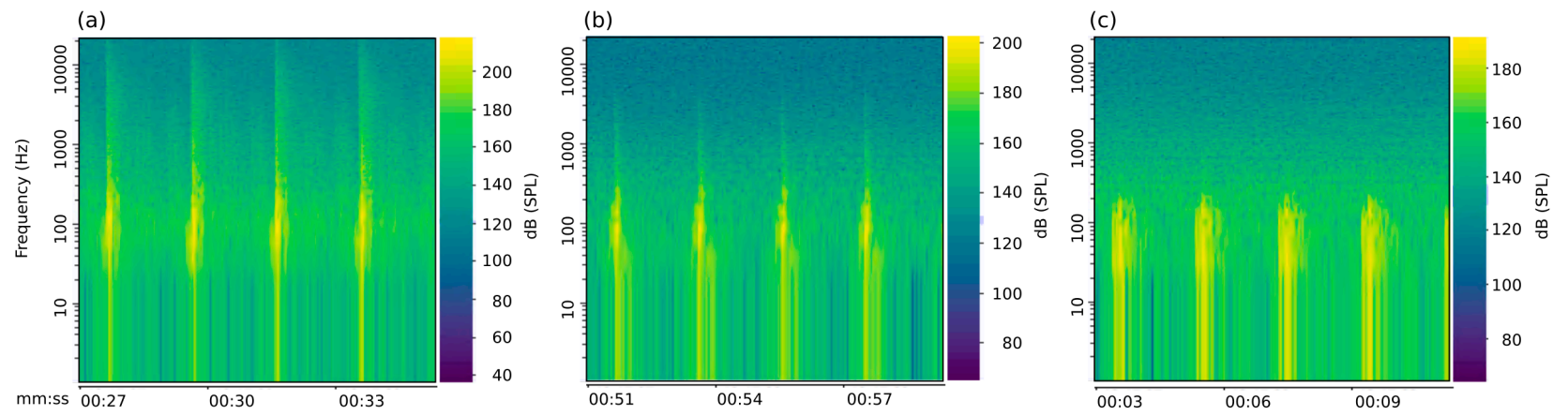

Figure 2. Narrow-band analysis (colour range in $\mathrm{dB}$ re $1 \mu \mathrm{Pa}$ ) showing a few hammer strokes for different noise abatement system configurations but comparable hammer energies, evaluated at $1500 \mathrm{~m}$ distance to the pile driving location. (a) Pile driving event 17 without noise abatement systems and a hammer energy of $2870 \mathrm{~kJ}$; (b) pile driving event 17 with IHC-NMS but without DBBC and a hammer energy of $2890 \mathrm{~kJ}$; and (c) pile driving event 23 with IHC-NMS and DBBC and a hammer energy of $2850 \mathrm{~kJ}$.

Figure 2a shows the unabated spectra of noise emissions for a sequence of four hammer strokes. The spectra for hammer strokes in presence of a single noise abatement system (IHC-NMS) and the combination of two systems (IHC-NMS and DBBC) is depicted in Figure $2 b, c$, respectively. Already with one noise abatement system, the sound emission of pile driving noise, measured at a distance of $1500 \mathrm{~m}$, is significantly reduced over the entire spectral range considered here (cf. colour bars in figure insets (a) and (b)), With the combination of two systems, the sound pressure level is reduced even further (cf. color bars in figure insets (b) and (c)). Only the combination of both noise abatement systems leads to compliance with the dual threshold values. Importantly, both configurations also yield a particularly strong decrease in measured sound pressure levels for the higher frequency range. The most significant energy reduction is observed at frequencies above approximately $250 \mathrm{~Hz}$ when both noise abatement systems are used (see figure inset (c)). In this case, There the acoustic emission of pile-driving noise at high frequencies can no longer be distinguished from the overall noise background.

For a quantification of the ratio between sound energy contained within a lowfrequency range $(<250 \mathrm{~Hz})$ and the entire frequency range, we consider a subset of pile driving events analysed in this study. Histograms presented in Figure 3 show the distribution of the energy ratio between the low-frequency range versus the entire frequency range for all strokes of six different pile driving events recorded at $1500 \mathrm{~m}$ distance. Consistently for the vast majority of mitigated hammer strokes during these pile driving events, more than $95 \%$ of the acoustic energy is confined to the frequency range below $250 \mathrm{~Hz}$. The few exceptions can be attributed to background noise at the measurement position and correspond to the first pile driving strokes with very low pile driving energy. Even for unmitigated pile driving, at least $85 \%$ of the stroke noise energy is found below $250 \mathrm{~Hz}$ for almost all hammer strokes (see pile 17). For pile 17, most of the unmitigated pile driving strokes yield between $87 \%$ and $97 \%$ of low-frequent energy, while strokes during the application of one noise abatement system mostly yield more than $97 \%$ of low-frequent energy. 

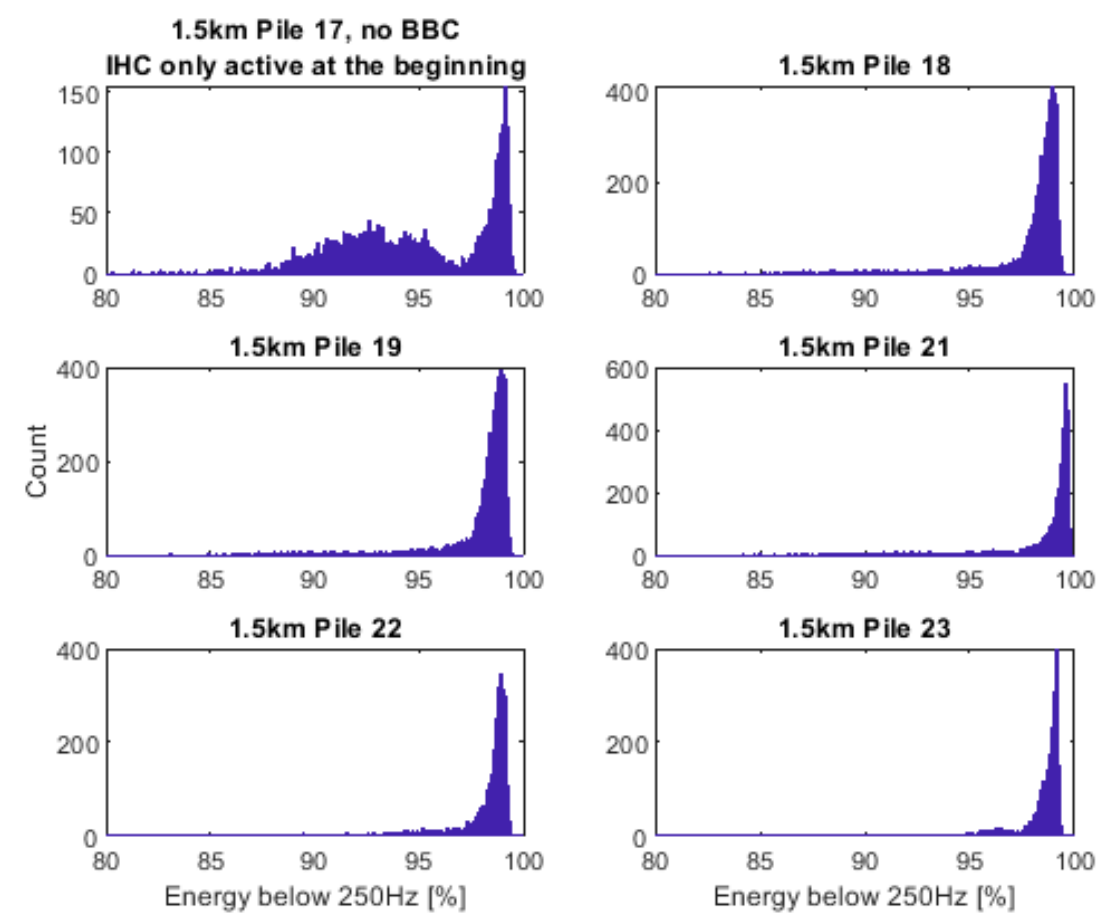

Figure 3. Histogram of the proportion of acoustic energy within the low-frequency range $(<250 \mathrm{~Hz})$ relative to the entire frequency range for all hammer strokes evaluated at $1500 \mathrm{~m}$ distance for selected pile driving events according to labels.

\subsection{Acoustic Pressure at Larger Distances to Piling Site as Revealed from Standardized Measurements at the Same Construction Project}

Here, data from a measuring station outside the construction site is primarily analysed in order to highlight effects related to the effectiveness of noise abatement systems used but also cumulative effects with noise from ship traffic in connection to the construction activities.

For the evaluation of the acoustic impact on the marine environment at larger distances to the piling locations, Figure 4 (top) depicts $\mathrm{SEL}_{05}$ and $\mathrm{L}_{\text {peak }}$ values at the temporary fixed monitoring station for the same pile driving events as shown in Figure 1. In Figure 4 (bottom) the corresponding distances between the evaluated pile driving location and the temporary fixed monitoring station are shown. For pile 17, corresponding to a distance of $11.3 \mathrm{~km}$, only the first part of the pile driving process was evaluated at the fixed station. This first part of the ramming includes all hammer strokes for which the IHC-NMS system was used for noise abatement. In contrast to the evaluation at $750 \mathrm{~m}$ (in Figure 1) and $1500 \mathrm{~m}$, which included the whole piling process, the unmitigated second part of the pile driving process could not be evaluated at the fixed measuring station. Due to the significantly higher sound pressure levels caused by the non-existing noise abatement system, the hydrophone was overdriven here (at a distance of $11.3 \mathrm{~km}$ ), so that the measured values were clipped.

Figure 4 shows that measured $\mathrm{SEL}_{05}$ and $\mathrm{L}_{\text {peak }}$ do not ony depend on the distance to the pile, but also on other factors (site and propagation path dependence), i.e., there is no monotonic relationship between measurements and distance. However, an overall decreasing trend between $\mathrm{SEL}_{05}$ or $\mathrm{L}_{\text {peak }}$ and distance can still be observed. As expected, results for pile driving event 17 (evaluated period with IHC-NMS system as single noise abatement system) yield higher values compared to other piling events in similar distances. Generally, measurement results do not only depend on e.g., dispersion and attenuation during sound propagation, but also on background noise at the measurement position. These factors contribute to the observed difference between $\mathrm{L}_{\text {peak }}$ and $\mathrm{SEL}_{05}$ at $750 \mathrm{~m}$ distance in comparison to the fixed measurement position. If measured levels were only 
dependent on the source, the difference between $\mathrm{L}_{\text {peak }}$ and $\mathrm{SEL}_{05}$ for piles in Figures 1 and 4 would be identical.

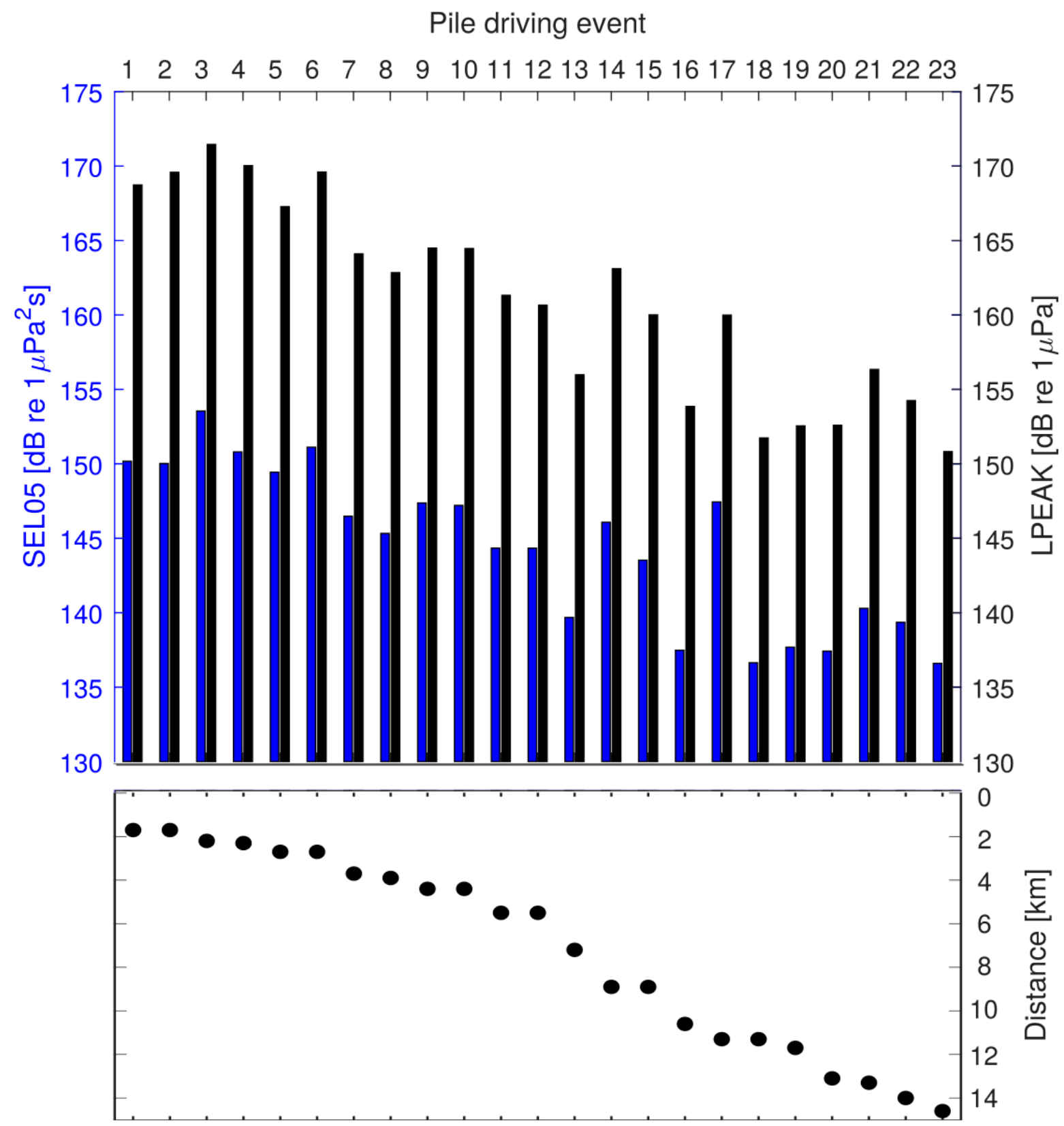

Figure 4. (top) $\mathrm{SEL}_{05}$ and $\mathrm{L}_{\text {peak }}$ values evaluated from acoustic monitoring data recorded at the temporary fixed monitoring station evaluated in this study. (bottom) Corresponding distances between the fixed monitoring station and the individual pile driving locations. Pile driving event number 17 corresponds to a test and reference measurement as detailed in the text.

We consider the dual threshold criterion, as described in Section 2, in terms of the distance dependent risk of injury due to the pile driving activity. Figure 5 shows the difference between measured $\mathrm{SEL}_{05}$ and $\mathrm{L}_{\text {peak }}$ values at our temporary fixed monitoring station and the dual threshold values defined for a distance of $750 \mathrm{~m}$ to the pile driving location. The risk for a harbour porpoise to experience injury due to a single exposure to a peak sound pressure level of $190 \mathrm{~dB}$ re $1 \mu \mathrm{Pa}$ or due to a cumulative exposure with a $\mathrm{SEL}_{05}$ of $160 \mathrm{~dB}$ re $1 \mu \mathrm{Pa}^{2} \mathrm{~s}$ may be excluded at all distance ranges to the piling location considered here (i.e., $>1.7 \mathrm{~km}$ ). 


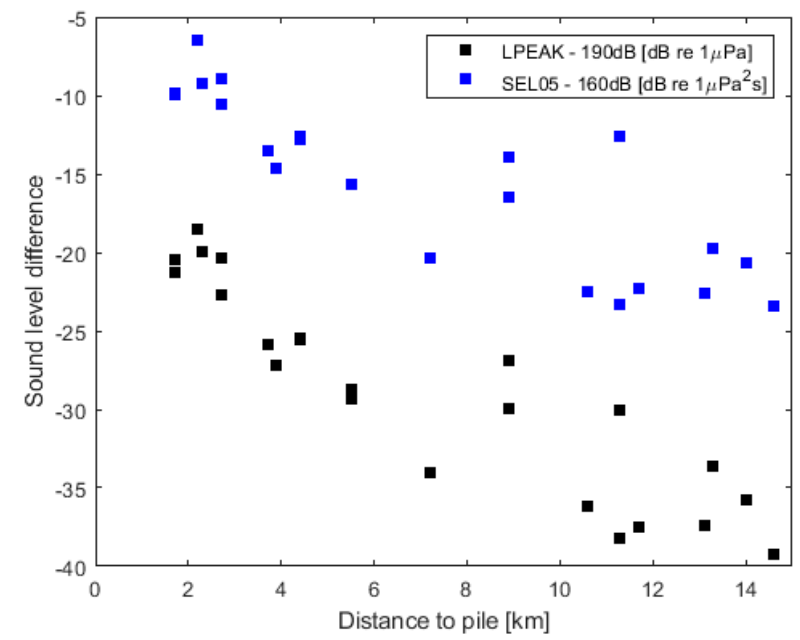

Figure 5. Difference between the measured $\mathrm{SEL}_{05}$ and $\mathrm{L}_{\text {peak }}$ at the temporary fixed monitoring station and the dual threshold values defined for a distance of $750 \mathrm{~m}$ to the pile driving location.

As mentioned above, we further observe a decreasing gap between $L_{\text {peak }}$ values and $\mathrm{SEL}_{05}$ values with distance. In agreement with the 3D propagation of the sound wave field, the signal waveform of the peak will be quickly altered with distance, while the evaluation of the SEL over an integration duration of $1 \mathrm{~s}$ still captures the signal energy of the impact. The $\mathrm{SEL}_{05}$ thus represents the stricter and more robust condition of the dual threshold criteria over a larger distance range.

For the uppermost end of our distance ranges, but especially for pile driving event 17 at a distance of $11.3 \mathrm{~km}$, we further noticed a decrease in the reliability of our automatic stroke detection algorithm, despite higher values of sound pressure due to the absence of a DBBC. The waveform of corresponding strokes differed from other pile driving events with both noise abatement systems, in agreement with the moderately higher frequency content for signals at pile 17 (cf. Figure 2b). Due to the remaining energy at higher frequencies, dispersion causes the broadening of wave packets for individual impacts at these greater distances. This characteristic implies that automatic signal detectors must be optimized and adapted to the desired distance ranges of monitoring. Furthermore, the determination of signal-to-noise ratios may be biased when evaluated locally around a stroke and the individual impacts recorded may start to overlap temporally before noise levels decay back to the background level.

For a distance range exceeding approximately $10 \mathrm{~km}$ to the pile driving location, signal-to-noise ratios for certain pile driving events were not sufficiently high to reliably detect hammer strokes. The lowermost signal-to-noise ratios were retrieved for two of the piling events in particular, events 18 and 23. Both piling events yield the lowest results for $\mathrm{L}_{\text {peak }}$ and $\mathrm{SEL}_{05}$ observed at the fixed monitoring station. However, these values fall not more than 1-2 $\mathrm{dB}$ below the next higher values observed for three other pile driving events $(16,19$, and 20). However, it is not the absolute sound level that is decisive for the success of an automatic detection, but the amplitude difference between the signal and the background noise. Therefore, we next examine the background sound level at the fixed measurement position a few hours before the onset of pile driving.

For this we consider the LEQ evaluated over time windows of $5 \mathrm{~s}$ length. Figure $6 \mathrm{a}$ shows the resulting LEQ during these time spans preceding the pile driving activity. Relatively high background noise levels are observed during all of the considered time spans. However, while background noise levels remain below a value of $130 \mathrm{~dB}$ on average for most cases considered here, they exceed this threshold during the majority of the $7 \mathrm{~h}$ before pile driving event 18 and surpass this threshold during the hour directly before the onset of pile driving event 23. In combination with the low $\mathrm{L}_{\text {peak }}$ and $\mathrm{SEL}_{05}$ levels, this explains the low SNR observed. An analysis of the significant wave height retrieved as hourly time series measured at the FINO 1 station in the southern North 
Sea [20], as depicted in Figure 6b, does not indicate a significant simultaneous increase in natural background noise due to an elevated sea state in the North Sea. Thus, it is reasonable to assume that these SPL fluctuations in the background sound level are an anthropogenic effect.
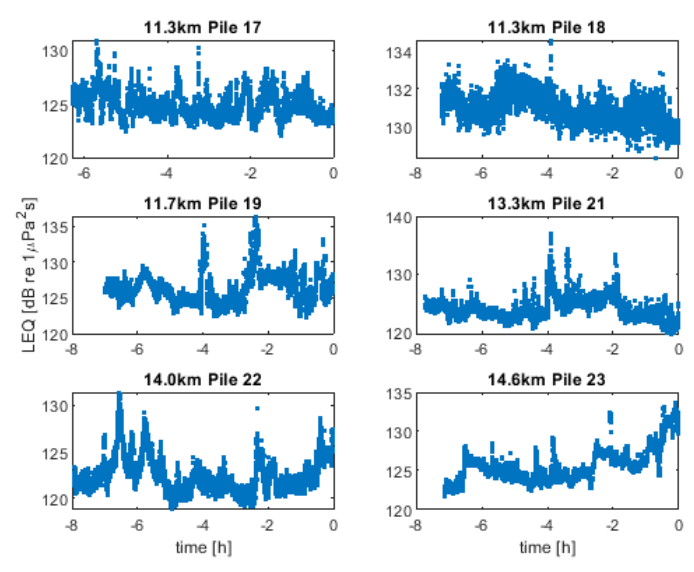

(a)
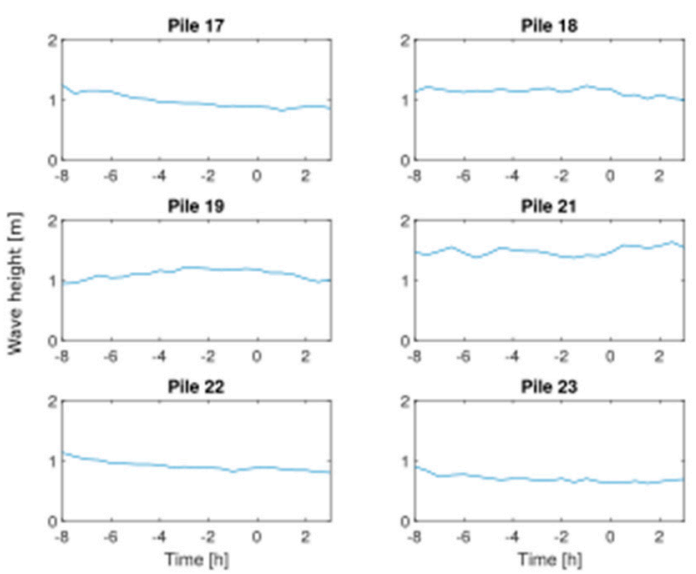

(b)

Figure 6. (a) LEQ evaluated over time windows of $5 \mathrm{~s}$ length during a few hours before the onset of pile driving at a subset of pile driving events. (b) Hourly time series of significant wave height at the BSH research platform FINO 1 retrieved via MarinEARS.

Furthermore, we do not observe a comparably disturbing and continuous background noise for the monitoring stations at closer distance ranges to the pile driving location. We therefore evaluate the spectral statistics of LEQ exceedance values of $5 \%, 50 \%$, and $95 \%$ at the fixed monitoring station during the same time span before the onset of pile driving. The corresponding spectral statistics are depicted in Figure $7 \mathrm{~b}$. For comparison, the broadband LEQ values are shown in Figure 6a. All of these spectral results yield a strikingly low variability, indicating the predominance of a relatively continuous spectral characteristic of the background soundscape, and which likely masks piling noise from the distant source locations. By examining the spectral statistics in Figure $7 \mathrm{~b}$, the background soundscape yields higher frequency components above $10 \mathrm{kHz}$, unlike the characteristic emissions of abated pile driving.

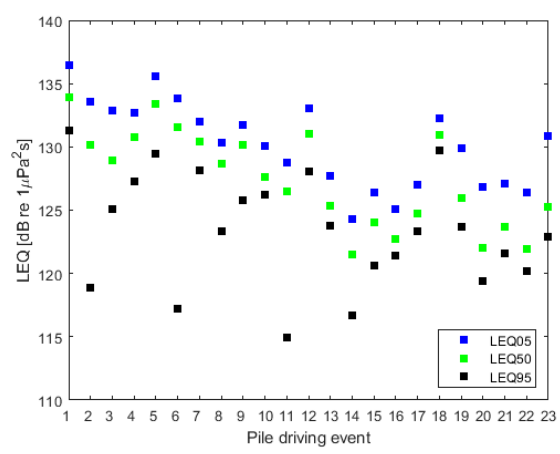

(a)
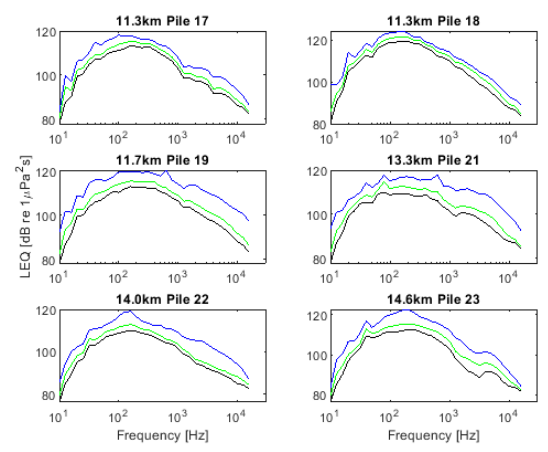

(b)

Figure 7. (a) Broadband LEQ exceedance values of 5\% (blue), 50\% (green), and 95\% (black) at the fixed monitoring station during the same time span before the onset of pile driving as shown in Figure 5. (b) Spectral statistics of the 1/3 octave band LEQ exceedance values of 5\% (blue), 50\% (green), and 95\% (black) at the fixed monitoring station during the same time span before the onset of pile driving as shown in Figure 5. 
We analysed the simultaneous processes and operations carried out in addition to the installation of the foundations in the construction project under study, as well as in immediately adjacent construction sites. This revealed that a total of 15 vessels were present within a radius of up to $10 \mathrm{~km}$ from the construction site. On average, three vessels were involved in the pile driving procedure directly: one construction vessel in jack up mode and two support vessels in DP mode: one for the operation of the bubble curtain and one for securing the construction site. Jacking up of construction vessels is a procedure observed to take one to two hours depending on vessel and site [28]. It is assumed, that jacking up and down activities may add to overall background noise substantially. The same is true for vessels with dynamic positioning (DP) systems. In addition, at distances of a few kilometres to our temporary monitoring station, installation work on turbines took place involving jack up vessels accompanied by smaller vessels for the transport of components. Furthermore, a construction vessel for cable laying as well as additional smaller vessels were present in the study area. Most likely, these additional noise sources dominate the background soundscape not only before the onset of pile driving, but also decrease the detectability of the impulsive pile driving signals.

\section{Discussion}

With the introduction of a noise emission threshold for impulsive noise due to pile driving, and the associated requirement for the application of technical noise abatement systems, one of the strictest regulations for this noise emitting activity has been established in Germany. Similar regulations and requirements were at the same time also developed in Belgium, in the Netherlands and in Denmark.

Establishing a clear protection target as described by the German Environment Protection Agency [29] and in the Concept for the Protection of harbour porpoise from underwater noise emissions from Offshore Pile driving [30] and a comprehensive monitoring program for the observation of the compliance and effectiveness of technological solutions, were the fuel and guide for innovation in Germany. Today, a number of commercially accessible noise abatement systems have been applied successfully on a standard basis in numerous wind farm projects [1,11].

Based on internationally available scientific knowledge and building on dedicated offshore research on options to reduce noise radiated into the environment more than 10 year ago, noise abatement and mitigation for pile driving procedures has been subject to a steep learning curve up to today's standard application of state-of-the-art offshore usable noise abatement technologies. In recent years, however, installation practices have further been adapted, including more efficient, temporally optimised and faster work processes, which implies a different intensity of activities at the con-struction sites as 10 years ago.

In the offshore wind energy development in Europe over the past decade, scientists, regulators and industry have successfully worked hand in hand to advance knowledge of the most relevant adverse effects of noise emissions from pile driving construction. Moreover, the cooperation between these groups has been crucial for the development of a mitigation strategy for relevant adverse effects and, especially, for the implementation of practical approaches to reduce the risk of impaired hearing and habitat loss to marine mammals, which were identified to be most vulnerable to the impulsive noise emissions from pile driving. This includes the harbour porpoise in particular, which is considered as an indicator species for impulsive noise [12]. At the same time, the use of noise abatement measures can substantially reduce or even avoid impacts on marine life (fish, invertebrates).

Due to the data availability through the comprehensive monitoring program of offshore wind farms under the regulation framework in Germany, recent studies have been able to analyse the effective impact ranges of harbour porpoise displacement based on the joint analysis of both, monitoring data of acoustics and harbour porpoise vocalisation for offshore wind farm (OWF) projects with and without noise mitigation in the German EEZ $[4,13]$. However, a most recent large scale study concludes that the effective displace- 
ment radii of harbour porpoise have not further decrease despite improvements in noise mitigation techniques [14].

In the following, we provide an overview of the prerequisites for establishing a command-and-control regulatory framework to reduce the impact of pile driving noise on marine ecosystems. These prerequisites for the introduction of a sustainable mitigation procedure include: (a) the description of the physical characteristics of the sound source to be mitigated, including knowledge of parameters such as intensity, frequency spectrum and duration of the event/s; (b) the identification of target species and knowledge on abundance and distribution patterns; (c) the evidence of adverse effects on target species by means of reliable and reproducible methods and (d) the consideration of potential mitigation measures.

A step-by-step approach may be followed for establishing an effective and practicable mitigation strategy based on the precautionary principle, covering all steps of the approval procedures for activities where significant impulsive noise emissions are expected. In this section, we outline eight steps for establishing mitigation procedures for pile driving activities in plans and approvals granted by regulatory agencies based on experiences gained in Germany:

Step (1) Develop scientific knowledge on species and habitats in the management area that may be affected: This step can be effectively initiated by the responsible agencies for the approval, environmental protection and nature conservation. A profound research basis may include ship- or aircraft-based surveys or acoustic investigations of priority species and may be strategically integrated into national monitoring and research programmes or specific site surveys. Another key component of the scientific knowledge base is targeted experimental work on noise sensitivity and hearing thresholds of species.

Step (2) Develop scientific knowledge on the physical characteristics of anthropogenic noise sources and on the transmission pathways into habitats: This step includes comprehensive research projects funded by the state and carried out by universities and research institutes. Importantly, this step needs to be repeated when construction site processes change or new technologies emerge.

Step (3) Adopt a noise mitigation strategy: This crucial step is led by the responsible agencies under consideration of: (a) the scientific knowledge developed in step 1 (species inventory, abundance and distribution); (b) the noise source and propagation loss characteristics investigated in step 2; (c) the information regarding threats to species and conservation status; (d) the requirements of European and national legislation and (e) the technical solutions (available or under development) to manage noise emissions and the applicability of measures in practice. The adopted strategy can be sustainable once it is robustly developed and only needs to be adapted or extended as necessary.

Step (4) Communicate the strategy and priority targets to stakeholders: Of particular importance is the timely communication of frameworks, targets, requirements and practical application issues to wind farm operators. Ongoing communication is necessary. However, the most intense communication phase takes place during the initial implementation phase.

Step (5) Develop technical noise abatement techniques: This step requires the joint cooperation and action of scientists, engineers and wind farm operators to develop noise abatement technologies. Research results (steps 1 and 2), the adopted noise mitigation strategy and the application framework defined in coordination with industry form the basis for technological developments and progress in field applications. The concerted action of all involved parties is the backbone for successful development.

Step (6) Develop normative rules to monitor the efficiency and effectiveness of measures: The adoption of standards for determining the performance of measures is A necessary step to take by approval and monitoring agencie. Standards for underwater noise measurements, for noise prognosis, for the quantitative determination of reduction potential of noise abatement systems and standards for the investigation of species abundance and distribution have to be in place to ensure the quality and comparability of monitoring data and assessments. 
Step (7) Establish an administrative basis: This step provides a basis for environmental impact assessments (EIA's), including risk-based assessments of noise emissions, participation processes, approval procedures, incidental conditions with noise emission thresholds at activity level and thresholds to prevent cumulative effects on habitats.

Step (8) Implementation in plans and approval procedures: Targets and objectives of the adopted noise mitigation strategy are integrated in all planning steps including maritime spatial planning, the site development plan for offshore wind energy and the site suitability assessment. Incidental conditions on noise mitigation are part of approvals granted and construction releases include detailed noise mitigation measures and monitoring requirements.

The noise mitigation strategy and the so called command and control regulation [25] on pile driving noise implemented in German waters but also similar regulations in other countries (e.g., Belgium, the Netherlands, Denmark) are based on the application of noise abatement and have promoted rapid development of the technology to the state-of-the-art for at least three abatement systems. In recent years, it has become apparent that noise reduction to protect marine ecosystems from impacts due to driving of jacket piles or large monopiles can be effective, applicable and affordable for the industry.

Since the foundation of structures requires several thousand hammer strokes, cumulative effects due to multiple impacts were acknowledged by setting a threshold as the $5 \%$ exceedance level $\left(\mathrm{SEL}_{05}\right)$ at $160 \mathrm{~dB}$ re $1 \mu \mathrm{Pa}^{2} \mathrm{~s}$, corresponding to a value $4 \mathrm{~dB}$ below the level which experimentally evoked TTS due to a single impulsive exposure. Cumulative effects on the key species harbour porpoise are further restricted according to the noise mitigation concept for the North Sea of the BMU [16,30], which limits the accepted acoustic pressure on habitats in terms of specific percentage-of-area thresholds applicable to the entire German EEZ and to certain nature conservation sites.

In our view, the application of the dual criterion based on unweighted broadband pressure level offer some strong advantages. Such criteria allow for broad development and application, and aim at reducing noise input in the marine ecosystem, and thus protect more marine species than frequency weighting for single species. What appears to be overregulation at a first glance, as described in [5], turns out to be an efficient measure for the marine ecosystem. Reduction of disturbance effects have so far been studied for the key species harbour porpoise. This is primarily due to availability of standard methods for such investigations. Even though a quantification of benefits for other marine species is lacking so far, it can be assumed that any substantial reduction of noise input in the marine environment is a good protective measure for the ecosystem.

Experiences so far shows how crucial it is from a regulatory perspective to implement norms and standards, since these are prerequisites for (a) a comparative evaluation between construction sites and their noise emissions; (b) the possibility of setting well defined thresholds and requirements and especially (c) for monitoring their compliance. In the context of pile driving and establishing the requirement of a field monitoring for noise reduction at the source, following aspects must be considered in the form of standardised procedures:

- the effectiveness of the noise-abatement and mitigation (e.g., deterrence) measures must be monitored and documented by means of measurements;

- a monitoring concept for assessing the effectiveness of measures must be submitted along with a noise mitigation concept and should be further concretised within the context of an implementation plan;

- concept and implementation plan for monitoring of underwater noise must be in accordance with standards, documented in a suitable manner and address constructionrelated noise due to vessels and due to pile-driving. During the execution of the noise-intensive works, underwater noise measurements should be performed at standardised distances (i.e., $750 \mathrm{~m}$ and $1500 \mathrm{~m}$ in Germany) to the source and in the nearest nature conservation area or an equivalent position for the purpose of habitat protection; 
- the effectiveness of measures must additionally be monitored by means of temporarily deployed harbor porpoise acoustic detectors. These monitoring stations should preferably be co-located with acoustic monitoring stations.

Here, we demonstrated the effectiveness of noise abatement systems applied during recent construction projects in the German Bight in a water depth of approximately $40 \mathrm{~m}$. We were able to confirm their significant reduction potential of sound pressure levels in comparison to unmitigated pile driving based on standardised monitoring data.

Building on recent results on effect ranges of mitigated and unmitigated pile driving [1,31-34], but also from the point of view of further construction sites in deeper waters with larger piles and heavy installation equipment, we have analysed potential noise sources that may have an impact on effect ranges despite the application of noise abatement systems. The study under [1] has shown that, according to recent underwater noise measurements, not only the number of vessels in and around the construction sites is important for background noise level, but also the type of drives, such as vessels with dynamic positioning systems (DP-system), as well as the use of underwater communication devices, such as echo sounders or sonars.

The analysis of potential sources of background noise during this study further revealed, that in addition to the pile driving, numerous other construction work processes took place, which increased the overall noise level. This includes turbine and rotor-blades installation, cable laying and preparatory processes ahead to operation. They may add substantially to noise levels. These sources are usually not included in noise emission and transmission loss modelling, which underlines the importance of sound measurements in the construction field. As shown in Section 3, pile driving was commonly conducted up to a significant wave height of $1.5 \mathrm{~m}$. This implies that increased background noise levels recorded at our fixed monitoring station cannot be attributed to increased ambient noise levels. Most likely, the cumulative emission of a number construction processes in the vicinity to the station may be responsible for the background noise levels observed. This is further supported by the fact that calm weather conditions allow for diverse installation works at the site.

The number of installation vessels present at a time at the construction site has varied from two up to four at a time. Including accompanying vessels for crew and material transfers, safety vessels, vessels for the deployment of bubble curtain and for monitoring activities. As observed from measurements in the immediate vicinity of pile driving sites noise levels already increase a few hours before piling starts. Jack-up operations of construction vessel and operation in DP-modus of accompanying ships further contribute to the recorded increased noise levels. Measurements at greater distance to the piling sites, on the other hand, revealed variably high noise levels, which could be related to jacking-up processes or DP-modus operations of construction vessels, cable laying and ship transfers. Consequently, the overall sound-scape at construction sites is highly variable in terms of sound intensities, so that mitigated piling noise may not be detectable at all due to the low signal-to-ratio. This may also have an impact on the perception by harbour porpoises. The avoidance observed even at well-mitigated piling sites could therefore be more related to the overall noise levels at construction sites where multiple installation and cable laying activities occur simultaneously. As the construction phase of wind farm projects becomes more efficient, meaning that installation work is conducted following a tighter schedule and a rather large number of ships are in use at the construction sites, it is likely that avoidance solely due to these activities will take place to some distance range. On the other hand, the increasing efficiency of installation procedures means that the overall duration of construction noise due to special vessels and activities decreases, which also shortens the duration of animal disturbance. These trade-offs will be subject to a future in depth analysis and need to be taken into account for a comprehensive interpretation of potential effects on marine species. 
Author Contributions: Conceptualisation, C.J.; software, B.S.; validation, B.S. and C.J.; formal analysis, B.S.; investigation, B.S. and C.J.; writing-original draft preparation, C.J.; writing-review and editing, B.S. and M.B.; visualisation, B.S.; supervision, C.J.; project administration, C.J. All authors have read and agreed to the published version of the manuscript.

Funding: This research received no external funding.

Institutional Review Board Statement: Not applicable.

Informed Consent Statement: Not applicable.

Data Availability Statement: The majority of data presented in this study are not publicly available due to restricted data sharing rules in the interest of national security and 3rd party data. Aggregated datasets presented in this study are publicly available. This data can be found here: https:/ / marinears. bsh.de (accessed on 29 July 2021).

Conflicts of Interest: The authors declare no conflict of interest.

\section{References}

1. Bellmann, M.A.; Brinkmann, J.; May, A.; Wendt, T.; Gerlach, S.; Remmers, P. Underwater Noise during the Impulse Pile-Driving Procedure: Influencing Factors on Pile-Driving Noise and Technical Possibilities to Comply with Noise Mitigation Values. 2020; Supported by the Federal Ministry for the Environment, Nature Conservation and Nuclear Safety (Bundesministerium für Umwelt, Naturschutz und Nukleare Sicherheit (BMU)), FKZ UM16 881500. Commissioned and Managed by the Federal Maritime and Hydrographic Agency (Bundesamt für Seeschifffahrt und Hydrographie (BSH)), Order No. 10036866. Available online: https:/ / www.itap.de/media/experience_report_underwater_era-report.pdf (accessed on 22 July 2021).

2. Dahl, P.H.; de Jong, C.A.; Popper, A.N. The underwater sound field from impact pile driving and its potential effects on marine life. Acoust. Today 2015, 11, 18-25.

3. Brandt, M.J.; Diederichs, A.; Betke, K.; Nehls, G. Responses of harbour porpoises to pile driving at the Horns Rev II offshore wind farm in the Danish North Sea. Mar. Ecol. Prog. Ser. 2011, 421, 205-216. [CrossRef]

4. Brandt, M.; Höschle, C.; Diederichs, A.; Betke, K.; Matuschek, R.; Nehls, G. Seal scarers as a tool to deter harbour porpoises from offshore construction sites. Mar. Ecol. Prog. Ser. 2013, 475, 291-302. [CrossRef]

5. Dähne, M.; Tougaard, J.; Carstensen, J.; Rose, A.; Nabe-Nielsen, J. Bubble curtains attenuate noise from offshore wind farm construction and reduce temporary habitat loss for harbour porpoises. Mar. Ecol. Prog. Ser. 2017, 580, 221-237. [CrossRef]

6. Boyd, I.; Brownell, B.; Cato, D.; Clarke, C.; Costa, D.; Evans, P.; Gedamke, J.; Gentry, R.; Gisiner, B.; Gordon, J.; et al. The Effects of Anthropogenic Sound on Marine Mammals. In EMB Position Paper 13; Connolly, N., Calewaert, J.-B., Eds.; Available online: http:/ / marineboard.eu/publication/effects-anthropogenic-sound-marine-mammal (accessed on 29 July 2021).

7. Finneran, J.J. Noise-induced hearing loss in marine mammals: A review of temporary threshold shift studies from 1996 to $2015 . J$. Acoust. Soc. Am. 2015, 138, 1702-1726. [CrossRef] [PubMed]

8. Effects of Anthropogenic Noise on Animals. In Springer Handbook of Auditory Research; Springer Science and Business Media LLC, 2018; pp. 277-309. Available online: https:/ / www.springer.com/gp/book/9781493985722 (accessed on 22 July 2021).

9. Popper, A.N.; Hawkins, A.D.; Thomsen, F. Taking the Animals' Perspective Regarding Anthropogenic Underwater Sound. Trends Ecol. Evol. 2020, 35, 787-794. [CrossRef] [PubMed]

10. Gomez, C.; Lawson, J.; Wright, A.; Buren, A.; Tollit, D.; Lesage, V. A systematic review on the behavioural responses of wild marine mammals to noise: The disparity between science and policy. Can. J. Zoöl. 2016, 94, 801-819. [CrossRef]

11. Southall, B.L.; Finneran, J.J.; Reichmuth, C.; Nachtigall, P.E.; Ketten, D.R.; Bowles, A.E.; Ellison, W.T.; Nowacek, D.P.; Tyack, P. Marine Mammal Noise Exposure Criteria: Updated Scientific Recommendations for Residual Hearing Effects. Aquat. Mamm. 2019, 45, 125-232. [CrossRef]

12. Koschinski, S.; Lüdemann, K. Noise Mitigation for the Construction of Increasingly Large Offshore Wind Turbines. In Technical Options for Complying with Noise Limits; The Federal Agency for Nature Conservation: Isle of Vilm, Germany, 2020; Available online: https: / / www.bfn.de/fileadmin/BfN/meeresundkuestenschutz/Dokumente/Noise-mitigation-for-the-constructionof-increasingly-large-offshore-wind-turbines.pdf (accessed on 29 July 2021).

13. De Jong, C.A.F.; Ainslie, M.A.; Blacquiere, G. Standard for Measurement and Monitoring of Underwater Noise, Part II: Procedures Formeasuring Underwater Noise in Connectionwith Offshore Wind Farm Licensing TNO Report, TNO-DV 2011 C251. 2011. Available online: https:/ / tethys.pnnl.gov/sites/default/files/publications/TNO-Report-2011.pdf (accessed on 22 July 2021).

14. BSH Offshore Wind Farms: Measuring Instruction for Underwater Sound Monitoring. Current Approach with Annotations, Application Instructions. 2011. Available online: https://www.bsh.de/DE/PUBLIKATIONEN/_Anlagen/ Downloads_Suchausschluss/Offshore/Anlagen-EN/Measuring-instruction-for-underwater-sound-monitoring.pdf?_blob= publicationFile\&v=4 (accessed on 22 July 2021).

15. NPL. Good Practice Guide for Underwater Noise Measurement; No. 133; 2014; ISSN 1368-6550. Available online: https: //www.npl.co.uk/special-pages/guides/gpg133underwater (accessed on 22 July 2021). 
16. ISO 18405:2017. Underwater Acoustics-Terminology. Available online: https://www.iso.org/standard/62406.html (accessed on 22 July 2021).

17. ISO 18406:2017-04: Underwater Acoustics-Measurement of Radiated Underwater Sound From Percussive Pile Driving. Available online: https: / / www.iso.org/standard/62407.html (accessed on 22 July 2021).

18. Reinhall, P.G.; Dahl, P.H. Underwater Mach wave radiation from impact pile driving: Theory and observation. J. Acoust. Soc. Am. 2011, 130, 1209-1216. [CrossRef] [PubMed]

19. Zampolli, M.; Nijhof, M.J.J.; De Jong, C.A.F.; Ainslie, M.A.; Jansen, E.H.W.; Quesson, B. Validation of finite element computations for the quantitative prediction of underwater noise from impact pile driving. J. Acoust. Soc. Am. 2013, 133, 72-81. [CrossRef] [PubMed]

20. Lippert, T.; Ainslie, M.A.; Von Estorff, O. Pile driving acoustics made simple: Damped cylindrical spreading model. J. Acoust. Soc. Am. 2018, 143, 310-317. [CrossRef] [PubMed]

21. Ainslie, M.A.; Halvorsen, M.B.; Müller, R.A.J.; Lippert, T. Application of damped cylindrical spreading to assess range to injury threshold for fishes from impact pile driving. J. Acoust. Soc. Am. 2020, 148, 108-121. [CrossRef] [PubMed]

22. Southall, B.L.; Bowles, A.E.; Ellison, W.T.; Finneran, J.J.; Gentry, R.L.; Green, C.R.J.R.; Kastak, D.; Ketten, D.R.; Miller, J.H.; Nachtigall, P.E.; et al. Marine mammal noise exposure criteria: Initial scientific recommendations. Aquat. Mamm. 2007, 33, 411-521. [CrossRef]

23. Finneran, J.J. Auditory Weighting Functions and TTS/PTS Exposure Functions for Marine Mammals Exposed to Underwater Noise. TECHNICAL REPORT 3026. 2016. Available online: https:/ /apps.dtic.mil/sti/citations/AD1026445 (accessed on 22 July 2021).

24. National Marine Fisheries Service. Technical Guidance for Assessing the Effects of Anthropogenic Sound on Marine Mammal Hearing: Underwater Acoustic Thresholds for Onset of Permanent and Temporary Threshold Shifts; NOAA Technical Memorandum NMFS-OPR55; United States Department of Commerce: Washington, DC, USA, 2018; 178p.

25. Merchant, N.D. Underwater noise abatement: Economic factors and policy options. Environ. Sci. Policy 2019, 92, 116-123. [CrossRef]

26. DIN EN ISO/IEC 17025:2018-03, Allgemeine Anforderungen an die Kompetenz von Prüf-und Kalibrierlaboratorien (ISO/IEC_17025:2017); Deutsche und Englische Fassung EN_ISO/IEC_17025:2017. EN ISO/IEC 2019, Volume 17025. Available online: https:/ / opus4.kobv.de/opus4-bam/frontdoor/index/index/docId/42383 (accessed on 28 July 2021).

27. DIN SPEC 45653:2017. Offshore Wind Farms-In-Situ Determination of the Insertion Loss of Control Measures Underwater. DIN/VDI-Normenausschuss Akustik, Lärmminderung und Schwingungstechnik (NALS). DIN Deutsches Institut für Normung e. V. Available online: https://webstore.ansi.org/standards/din/dinspec456532017 (accessed on 22 July 2021).

28. MarinEARS. Available online: https:/ / MarinEARS.bsh.de (accessed on 12 June 2021).

29. Umweltbundesamt, 2011. Empfehlung von Lärmschutzwerten bei der Errichtung von Offshore-Windenergieanlagen (OWEA). Umweltbundesamt. Available online: www.umweltbundesamt.de (accessed on 28 July 2021).

30. BMU. Konzept für den Schutz der Schweinswale vor Schallbelastungen bei der Errichtung von Offshore-Windparks in der deutschen Nordsee (Schallschutzkonzept), Bundesministerium für Umwelt, Naturschutz und Reaktorsicherheit. 2013. Available online: https:/ / www.bfn.de/fileadmin/BfN/awz/Dokumente/schallschutzkonzept_BMU.pdf (accessed on 22 July 2021).

31. Lucke, K.; Lepper, P.A.; Blanchet, M.A.; Siebert, U. Temporary shift in masked hearing thresholds in a harbor por-poise (Phocoena phocoena) after exposure to seismic airgun stimuli. J. Acoust. Soc. Am. 2009, 125, 4060-4070. [CrossRef] [PubMed]

32. Brandt, M.; Dragon, A.; Diederichs, A.; Bellmann, M.; Wahl, V.; Piper, W.; Nabe-Nielsen, J.; Nehls, G. Disturbance of harbour porpoises during construction of the first seven offshore wind farms in Germany. Mar. Ecol. Prog. Ser. 2018, 596, $213-232$. [CrossRef]

33. Rose, A.; Brandt, M.J.; Vilela, R.; Diederichs, A.; Schubert, A.; Kosarev, V.; Nehls, G.; Volkenandt, M.; Wahl, V.; Michalik, A.; et al. Effects of Noise-Mitigated Offshore Pile Driving on Harbour Porpoise Abundance in the German Bight 2014-2016 (Gescha 2) -Assessment of Noise Effects, Technischer Abschlussbericht im Auftrag des Arbeitskreis Schallschutz" des Offshore Forums Windenergie, Erstellt von BioConsult SH GmbH \& Co KG, Husum; IBL Umweltplanung $\mathrm{GmbH}$, Oldenburg; Institut für Angewandte Ökosystemforschung GmbH, Hamburg. 2019. Available online: https / / bwo-offshorewind.de/wp-content/uploads/2019/07/study-on-the-effects-of-noise-mitigated-construction-workson-the-harbour-porpoise-population-in-the-german-north-sea.pdf (accessed on 28 July 2021).

34. Lucke, K.; Lepper, P.A.; Blanchet, M.; Siebert, U. Testing the acoustic tolerance of harbour porpoise hearing for impulsive sounds. J. Acoust. Soc. Am. 2008, 123, 3780. [CrossRef] 